\title{
Generating Highly Specific Spectra and Identifying Thermal Decomposition Products via Gas Chromatography / Vacuum Ultraviolet Spectroscopy (GC/VUV): Application to Nitrate Ester Explosives
}

\author{
Courtney A. Cruse, John V. Goodpaster* \\ Department of Chemistry and Chemical Biology, Indiana University - Purdue University Indianapolis (IUPUI), 402 North \\ Blackford Street LD326, Indianapolis, Indiana 46202, United States
}

* Corresponding Author. E-mail address: jvgoodpa@iupui.edu (J. V. Goodpaster).

\begin{abstract}
:
Gas chromatography/mass spectrometry (GC/MS) is a "workhorse" instrument for chemical analysis, but it can be limited in its ability to differentiate structurally similar compounds. The coupling of GC to vacuum ultraviolet (VUV) spectroscopy is a recently developed technique with the potential for increased detection specificity. To date, GC/VUV has been demonstrated in the analysis of volatile organic compounds, petroleum products, aroma compounds, pharmaceuticals, illegal drugs, and lipids. This paper is the first to report on the utility of GC/VUV for explosives analysis in general, and the first to report on thermal degradation within the VUV cell and its analytical utility. The general figures of merit and performance of GC/VUV were evaluated with authentic standards of nitrate ester explosives (e.g., nitroglycerine (NG), ethylene glycol dinitrate (EGDN), pentaerythritol tetranitrate (PETN), and erythritol tetranitrate (ETN)). In addition, the explosive analytes were thermally degraded in the VUV cell, yielding reproducible, complex and characteristic mixtures of gas phase products (e.g., nitric oxide, carbon monoxide, and formaldehyde). The relative amounts of the degradation products were estimated via spectral subtraction of library spectra. Lastly, GC/VUV was used to analyze milligram quantities of intact and burned samples of double-base smokeless powders containing nitroglycerine, diphenylamine, ethyl centralite, and dibutylphthalate
\end{abstract}

KEYWORDS. Gas Chromatography, Vacuum Ultraviolet Spectroscopy, Nitrate Ester Explosives, Thermal Degradation.

1. Introduction

A recent development with the potential to complement mass spectrometry is a benchtop vacuum ultraviolet (VUV) detector for GC (GC/VUV). The VUV (VGA101) detector acquires gas phase absorption data between 125 and $430 \mathrm{~nm}$. In this region, $\sigma$ to $\sigma^{*}, \mathrm{n}$ to $\pi^{*}$, and high probability $\pi$ to $\pi^{*}$ transitions are evident. ${ }^{1-2}$ Prior to this, a bright source synchrotron facility was required to obtain absorption information in this low wavelength region. ${ }^{1,3}$ Prior research has shown that gas phase absorption spectra in the 125 to $240 \mathrm{~nm}$ range are highly informative due to the presence of $\sigma$ to $\sigma^{*}$ transitions originating primarily from C-C and C-H bonds. ${ }^{4} \mathrm{As}$ the spectra are acquired in the gas phase, no interactions occur between species; thus spectra will not shift or smear like in liquid phase spectroscopy. ${ }^{5}$ Furthermore, the molecular absorption cross section in this region allows for orders of magnitude larger sensitivity than those in the ultraviolet and infrared regions. ${ }^{6}$ Additionally, VUV has the ability to deconvolute species in a single peak. ${ }^{3,5,7-8}$ This originates from the additive nature of the Beer Lambert Law where the total absorption is a linear combination of each, non-interacting species. ${ }^{2-5,9-10}$ To date, GC/VUV has been used to analyse drugs, ${ }^{2,11}$ fatty acid methyl esters, ${ }^{9}$ diesel fuel, ${ }^{3,6-7 \text {, }}$ ${ }^{10}$ hydrocarbons, ${ }^{12}$ and perfume and essential oil ${ }^{4,13}$ from 125 to $230 \mathrm{~nm}$.

Ultimately, explosives analysis requires high sensitivity, selectivity, and specificity. Towards that end, gas chromatography / mass spectrometry (GC/MS) is one of the current "gold standard" methods for the analysis of semi-volatile and volatile explosives. ${ }^{1,5,14}$ That being said, the analysis of nitrate ester explosives is inherently more difficult via GC/MS. For example, nitrate ester explosives are thermally labile and are prone to decomposition in the GC inlet. This can be largely overcome by using a multi-mode inlet with a temperature program and a shorter column.${ }^{15}$ However, these analytes have essentially identical mass spectra by electron ionization (EI) due to extensive fragmentation into $\mathrm{NO}_{2}{ }^{+}$at $\mathrm{m} / \mathrm{z} 46$ (as the base peak) and $\mathrm{CH}_{2} \mathrm{ONO}_{2}{ }^{+}$at $\mathrm{m} / \mathrm{z} 76$ without a molecular ion. ${ }^{14-16} \mathrm{In}$ negative-ion chemical ionization (NCI), fragmentation of nitrate ester explosives results in ions for $\mathrm{ONO}_{2}{ }^{-}$at $\mathrm{m} / \mathrm{z} 62$ and $\mathrm{NO}_{2}{ }^{-}$at $\mathrm{m} / \mathrm{z} 46$. When dichloromethane is used as the reagent gas, an $[\mathrm{M}+\mathrm{Cl}]^{-}$adduct is seen at $\mathrm{m} / \mathrm{z} 262 / 264{ }^{4}$

Analysis of nitrate ester explosives by liquid chromatography/mass spectrometry (LC/MS) is also possible using either electrospray ionization (ESI) or atmospheric pressure chemical ionization (APCI). LC/MS overcomes the issue of thermal decomposition in GC/MS. In some cases, post-column introduction of chemical additives are necessary for the identification of EGDN, NG, and PETN. ${ }^{15}$ According to the Technical Working Group for Fire and Explosive Analysis (TWGFEX), GC/MS and LC/MS are 
categorized as Category 1 (provide significant structural/element information) and Category 2 (provide limited structural/element information), respectively. ${ }^{17}$ Most recently, ambient ionization using desorption electrospray ionization (DESI) ${ }^{18}$ and lowtemperature plasma (LTP) ${ }^{19}$ have been used to identify PETN with MS/MS analysis. Direct analysis in real time (DART)/MS and surface-assisted laser desorption/ionization (SALDI)/TOF/MS analysis of explosives, including NG and PETN, has also been used. ${ }^{20}$ In these cases, there is no chromatographic separation and these techniques have yet to become generally available to and accepted by forensic scientists.

Andrasko et al. were the first to demonstrate that thermal decomposition of explosives can occur in GC with a UV detector with a spectral range of 178-330 nm. ${ }^{21}$ In particular, they observed that at higher transfer line temperatures, nitrate ester explosives such as ethylene glycol dinitrate (EGDN), nitroglycerine (NG), and pentaerythritol tetranitrate (PETN) decomposed into nitric oxide, which was easily detectable in their spectral range. This has informed our approach, but due to a wider spectral range $(125 \mathrm{~nm}-430 \mathrm{~nm})$ and other factors, we have identified several additional thermal degradation products of this class of explosives as well as estimates of their relative concentrations.

The aim of this work is to use GC/VUV to generate spectra at different transfer line and flow cell temperatures to investigate the thermal decomposition of analytes. Our application of interest has not been previously explored using GC/VUV, and that is the identification of explosives in intact, post-burn and post-blast samples. Hence, realistic samples of unburned and burned doublebase smokeless powders have been analysed to demonstrate the application of GC/VUV to forensic explosives analysis. To the best of our knowledge, this is the first published application of GC/VUV to the analysis of explosives.

\section{Materials and Methods}

\subsection{Chemicals}

Pentane (pesticide grade), methanol (optima LC/MS), and dichloromethane (stabilized HPLC grade) were purchased from Fisher Scientific. Nitroglycerine $(1000 \mu \mathrm{g} / \mathrm{mL}$ in methanol), erythritol tetranitrate $(1000 \mu \mathrm{g} / \mathrm{mL}$ in acetonitrile), ethylene glycol dinitrate $(1000 \mu \mathrm{g} / \mathrm{mL}$ in methanol), and pentaerythritol tetranitrate $(1000 \mu \mathrm{g} / \mathrm{mL}$ in methanol) were purchased from Restek as singlecomponent standards. Ethyl centralite was purchased from Aldrich Chemistry, diphenylamine was purchased from Acros Organics, and dibutyl phthalate was purchased from Supelco. Double-base smokeless powders (Alliant Red Dot, Accurate No. 7, and Accurate No. 5) were purchased locally. All $9 \mathrm{~mm}$ screw thread liquid injection vials were purchased from Fisher Scientific.

\subsection{Sample Preparation}

A mixture of nitroglycerine (NG), erythritol tetranitrate (ETN), ethylene glycol dinitrate (EGDN), and pentaerythritol tetranitrate (PETN) was prepared containing $250 \mathrm{ppm}$ of each analyte. ETN in acetonitrile was first evaporated and reconstituted in methanol using a nitrogen blowdown apparatus. Additionally, single component samples of NG, ETN, EGDN, PETN were prepared at 1000 ppm in methanol and diluted 100 -fold to $10 \mathrm{ppm}$.

Realistic samples were prepared by weighing out approximately $0.6 \mathrm{mg}$ of each double-base smokeless powder (approximately 5 particles). The particles were extracted with $3 \mathrm{~mL}$ of dichloromethane (DCM) for an hour on a shaker table. Then, the DCM extract was filtered with a $0.45 \mu \mathrm{m}$ PTFE filter and injected into the GC/VUV for analysis of smokeless powder components. The burned double-base smokeless powder samples were created by weighing out $50 \mathrm{mg}$ of each double-base smokeless powder onto a watch glass. Then, the sample was ignited and allowed to self-extinguish. The residue was scraped from the watch glass and extracted with $1 \mathrm{~mL}$ of DCM for one hour. After filtering, the extract was analysed in the same manner as the intact smokeless powder.

\subsection{Gas Chromatography}

Each experiment was run in triplicate with a methanol blank run between each set of triplicates. $1 \mu \mathrm{L}$ of the mixture solution was injected into the gas chromatograph with hydrogen as the carrier gas at $1.8 \mathrm{~mL} / \mathrm{min}$ (Agilent $7890 \mathrm{~B}$ series $\mathrm{GC}$ equipped with a multimode inlet and Agilent 7390 autosampler). A ramped inlet temperature program was utilized $\left(50{ }^{\circ} \mathrm{C}\right.$ ramped to $280{ }^{\circ} \mathrm{C}$ at 900 ${ }^{\circ} \mathrm{C} / \mathrm{min}$ ) with a split injection $(5: 1) .{ }^{22}$ Analytes were separated on a Phenomenex ZB-5MS column $(10 \mathrm{~m} \times 0.18 \mathrm{~mm} \times 0.18 \mu \mathrm{m})$. For the mixture of EGDN, ETN, NG, and PETN, the oven program began at $60{ }^{\circ} \mathrm{C}$ for $0.5 \mathrm{~min}$, ramped at $20{ }^{\circ} \mathrm{C} / \mathrm{min}$ to $170{ }^{\circ} \mathrm{C}$. Realistic double-base smokeless powders were analysed with an oven program of $60^{\circ} \mathrm{C}$ for $0.5 \mathrm{~min}$, ramped at $20{ }^{\circ} \mathrm{C} / \mathrm{min}$ to 220 ${ }^{\circ} \mathrm{C}$.

\subsection{Vacuum Ultraviolet Spectroscopy.}

After the GC effluent exited the transfer line, it was directed into a VUV Analytics VGA-101 VUV spectrometer with a spectral resolution of approximately $0.5 \mathrm{~nm}$. All experiments were run with a spectral range of $125 \mathrm{~nm}$ to $430 \mathrm{~nm}$ with a $4.5 \mathrm{~Hz}$ scan rate, nitrogen as the make-up gas at a pressure of $0.35 \mathrm{psi}$, and a deuterium lamp as the light source. The transfer line and flow cell were adjusted, in tandem, for each triplicate run to $190^{\circ} \mathrm{C}, 200{ }^{\circ} \mathrm{C}, 220{ }^{\circ} \mathrm{C}, 240{ }^{\circ} \mathrm{C}, 260{ }^{\circ} \mathrm{C}$, and $280{ }^{\circ} \mathrm{C}$. This was done to observe the thermal decomposition products of the nitrate esters in the VUV flow cell. 


\subsection{Ultraviolet/Visible Spectroscopy.}

Each sample was analyzed by a Thermo Scientific Evolution 201 UV-Visible Spectrophotometer with a scan range of $230 \mathrm{~nm}-700$ $\mathrm{nm}$ and a spectral bandwidth of $1.0 \mathrm{~nm}$. Quartz cuvettes were utilized for spectral acquisition. The UV cut off for methanol (205 $\mathrm{nm}$ ) is below the range of the UV-Vis instrument.

\subsection{Spectral Math}

Software for a Fourier Transform Infrared Spectrometer (FTIR), OMNIC Picta, was utilized to perform spectral subtraction on the VUV spectra at $280^{\circ} \mathrm{C}$ to determine the relative contribution of each decomposition product to the nitrate ester spectra. This could be accomplished according to the Beer-Lambert law following the equation: Spectrum $1-\left(\right.$ Spectrum $2 *$ Factor) $=$ Result. ${ }^{23}$ The multiplication factor is determined by subtracting out spectrum 2 until the common peak(s) are, ideally, zeroed from spectrum 1. Using this approach, the thermal decomposition products were subtracted one at a time from the initial spectrum. The squared correlation coefficient $\left(\mathrm{r}^{2}\right)$ and the sum-squared residuals (SSR) were calculated for the experimental VUV spectrum relative to the sum of the thermal decomposition components.

\subsection{Calculations}

For calculations of signal-to-noise $(\mathrm{S} / \mathrm{N})$ ratio a single wavelength filter $(128-129 \mathrm{~nm})$ was considered. Signal was defined as the chromatographic peak height. Noise was defined as the standard deviation of ten baseline points that preceded the chromatographic peak. Seven calibration concentrations from $50 \mathrm{ppm}$ to $1000 \mathrm{ppm}$ run in triplicate were utilized for the calculations. A S/N ratio plot was constructed as $\log (\mathrm{S} / \mathrm{N})$ vs $\log (\mathrm{S})$. The limit of detections (LODs) were determined as the concentration with a $\mathrm{S} / \mathrm{N}$ equal to 3 from the $\mathrm{S} / \mathrm{N}$ plot.

\section{Results and Discussion}

\subsection{GC/VUV Analysis of EGDN, ETN, NG, and PETN}

Under the chromatographic conditions used here, the retention times for EGDN, NG, ETN, and PETN were $1.4 \mathrm{~min}, 3.4 \mathrm{~min}, 4.8$ min, and $5.7 \mathrm{~min}$, respectively. Standard VUV spectra were obtained for EGDN, NG, and ETN at flow cell temperatures of $170^{\circ} \mathrm{C}$ and at $190^{\circ} \mathrm{C}$ for PETN. As shown in Table 1, each VUV spectrum had two peak maxima around $135 \mathrm{~nm}$ and $187-188 \mathrm{~nm}$, respectively.

Table 1. Experimentally determined wavelengths of maximum absorbance $\left(\lambda_{\max } \pm 95 \%\right.$ confidence interval $)$ of EGDN, ETN, EGDN, and PETN in the VUV at $190^{\circ} \mathrm{C}(\mathrm{n}=3)$. In methanol, the $\boldsymbol{\lambda}_{\max }$ of these compounds are found at $278-280 \mathrm{~nm}$ (data not shown).

\begin{tabular}{|c|c|c|c|}
\hline & $\begin{array}{c}\text { Molecular Weight } \\
(\mathrm{g} / \mathrm{mol})\end{array}$ & Structure & $\begin{array}{c}\text { VUV } \\
\lambda_{\max }(\mathrm{nm})\end{array}$ \\
\hline 㤂 & 152.1 & & $\begin{array}{l}134.9 \pm 0.2 \\
187.3 \pm 0.4\end{array}$ \\
\hline Z & 227.09 & & $\begin{array}{c}135.1 \pm 0.5 \\
187.2 \pm 1.1\end{array}$ \\
\hline$\underset{\mathrm{Z}}{\mathrm{Z}}$ & 302.11 & & $\begin{array}{c}134.9 \pm 0.2 \\
187.7 \pm 0.3\end{array}$ \\
\hline
\end{tabular}




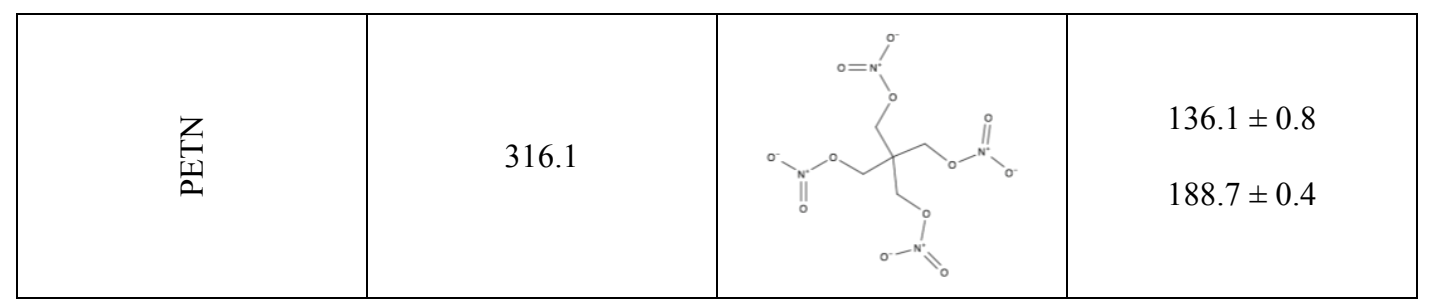

The linear range, $\mathrm{R}^{2}$, and slope for each analyte was determined from a calibration curve of peak area (at 128-129 nm) versus the concentration in ppm. Signal to noise was defined as the ratio of the height of a chromatographic peak divided by the standard deviation of the baseline noise preceding the peak. Plots of the log of the $\mathrm{S} / \mathrm{N}$ ratio versus the log of the signal were constructed and confirmed that the $\mathrm{S} / \mathrm{N}$ and $\mathrm{S}$ are linearly related and, hence, the instrument is blank noise limited. The calculated limit of detection for each compound (where $\mathrm{S} / \mathrm{N}=3$ ) is shown in Table 2 .

Table 2. Linearity, linear range, limit of detection and sensitivity of GC/VUV for EGDN, ETN, EGDN, and PETN.

\begin{tabular}{ccccc}
\hline Compound & Calculated LOD (ppm) & Linear Range (ppm) & $\mathbf{R}^{2}$ & $\begin{array}{c}\left.\text { Slope } \mathbf{( p p m}^{-1}\right) \\
\mathbf{X ~ 1 0 0}\end{array}$ \\
\hline EGDN & 17.5 & 25 to 1000 & 0.9993 & 2.84 \\
NG & 33.4 & 50 to 1000 & 0.998 & 2.38 \\
ETN & 174.3 & & & \\
PETN & & 250 to 1000 & 0.9996 & 1.29 \\
\hline
\end{tabular}

With increasing molecular weight, the LOD listed in Table 2 exhibits an upward trend and sensitivity exhibits a downward trend. This may be due to factors unrelated to the VUV detector, such as decreased efficiency of transfer of the analyte from the inlet to the stationary phase (i.e., discrimination effects related to volatility). A full optimization of inlet temperature and other parameters is planned to explore these effects. Another potential effect is that the thermal stability of these explosives decreases with increasing molecular weight, meaning degradation in the inlet would be more pronounced for ETN and PETN. A small peak that was specifically associated with PETN and deduced to be a degradation product formed in the inlet was observed.

When the VUV spectra of the nitrate esters are compared side-by-side with the EI mass spectra obtained from each compound, the difficulty in differentiating these explosives by either method is clear (see Figure 1). 

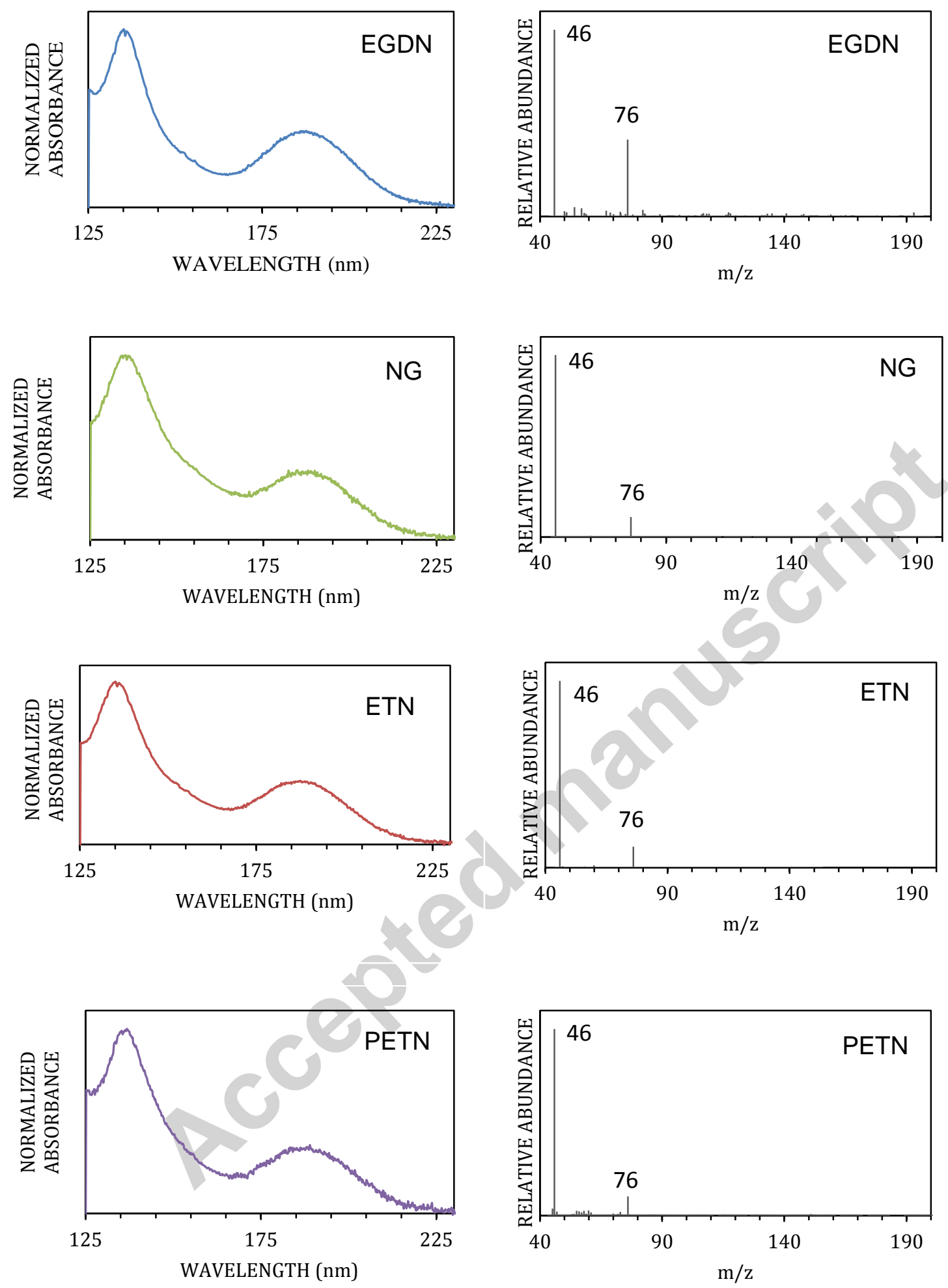

Fig. 1. Comparison of "as is" VUV spectra at $190{ }^{\circ} \mathrm{C}$ and EI mass spectra for nitrate ester explosives.

Spectra at $190{ }^{\circ} \mathrm{C}$ have more broad spectral features but differences are apparent in the relative peak height ratios of the two peaks and in the valley between the peaks, which allows for differentiation between EGDN, ETN, NG, PETN at $190{ }^{\circ} \mathrm{C}$ (see Figure 2 ). 


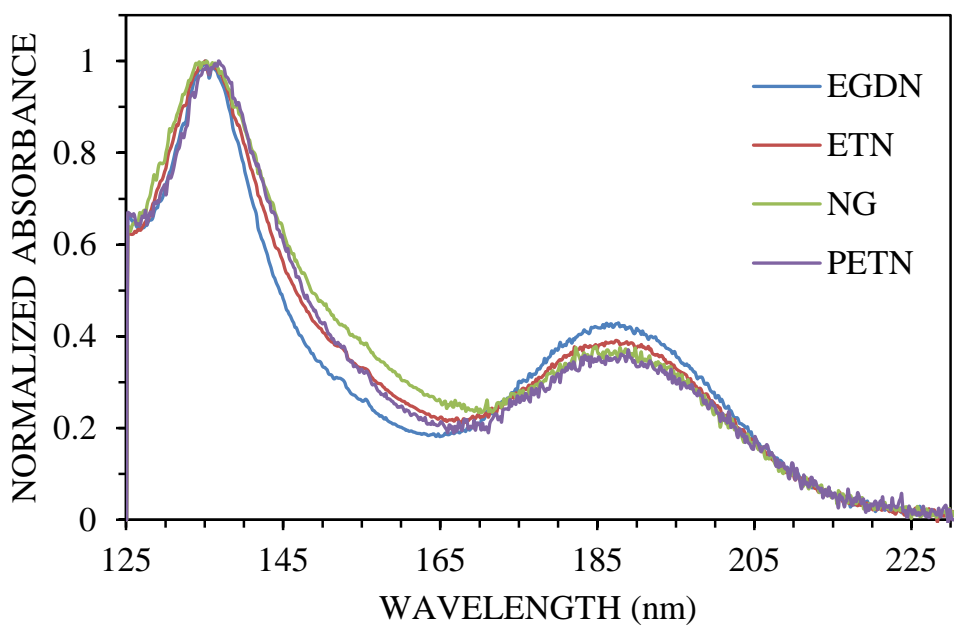

Fig. 2. Overlay of VUV spectra of EGDN, NG, ETN, and PETN at $190{ }^{\circ} \mathrm{C}$ demonstrates the subtle and reproducible differences in the spectra.

\subsection{Identification of Thermal Decomposition Products}

A critical discovery was that increasing the VUV flow cell temperature led to dramatic changes in the VUV spectra. This phenomenon is linked to the thermal decomposition of the four nitrate ester explosives. The decomposition process can be localized to the flow cell, rather than in the GC inlet, as a single peak was observed for each explosive in the chromatogram. Partial decomposition was observed at $220^{\circ} \mathrm{C}$ and nearly complete decomposition was observed at $280^{\circ} \mathrm{C}$ (Figure 3 ). All spectra were truncated after $240 \mathrm{~nm}$ due to the lack of any spectral features at longer wavelengths.
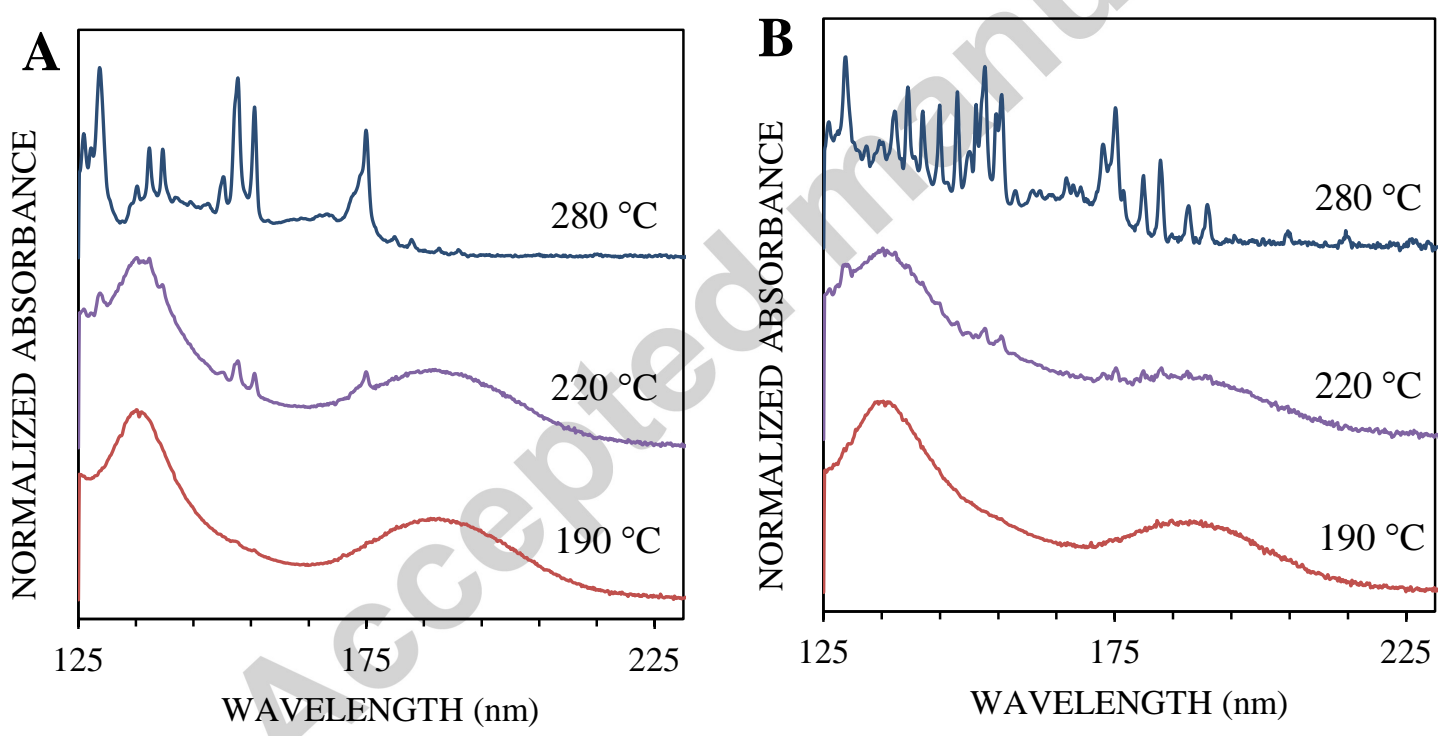

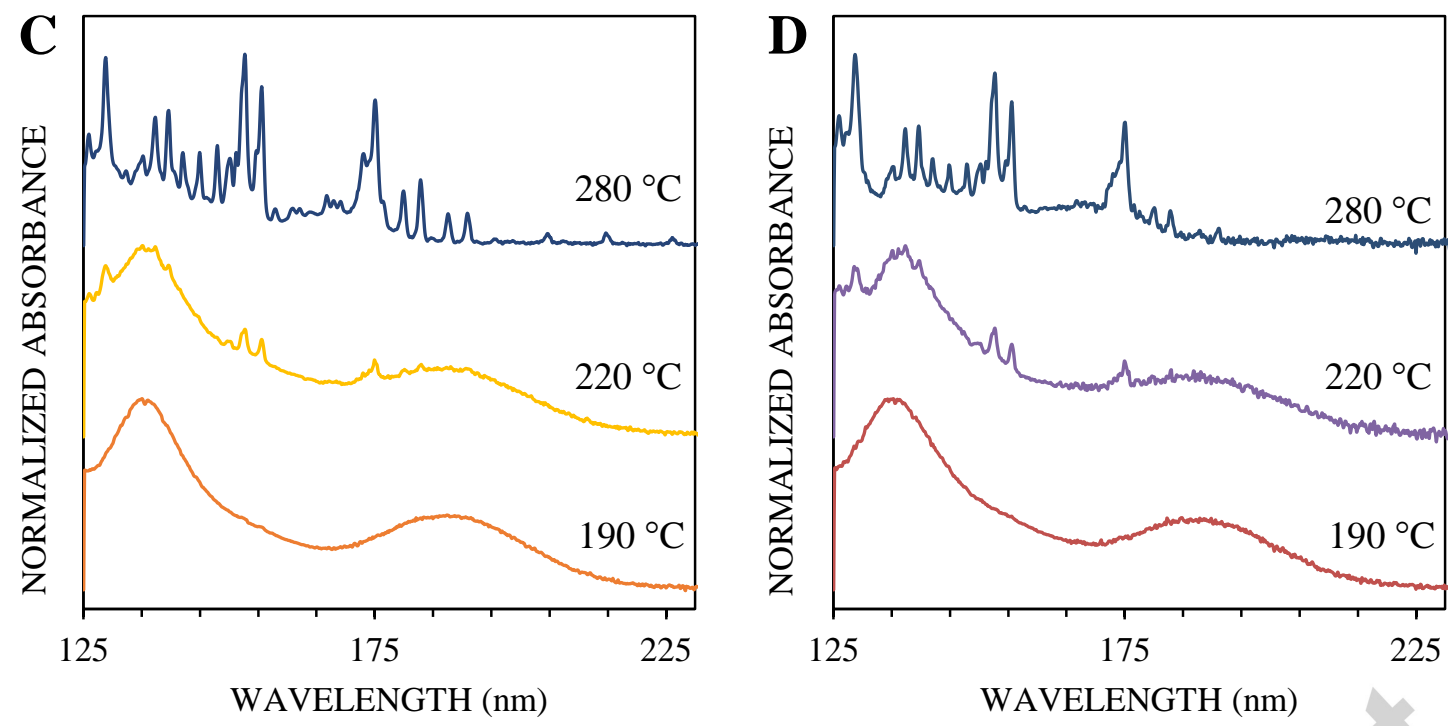

Fig. 3. Stacked VUV spectra of (A) EGDN ( $\left.T_{\text {dec }}=198\right)$, (B) NG $\left(T_{d e c}=167\right),(C)$ ETN $\left(T_{d e c}=170\right)$, and (D) PETN ( $\left.T_{\text {dec }}=157\right)$ at $190{ }^{\circ} \mathrm{C}$ (bottom), $220{ }^{\circ} \mathrm{C}$ (middle), and $280{ }^{\circ} \mathrm{C}$ (top). Decomposition temperatures are derived from Differential Scanning Calorimetry (DSC). ${ }^{24,25}$

Using a searchable VUV library, known decomposition products were compared to the decomposition spectra of EGDN, ETN, NG, and PETN. For example, we found that the spectral features in the decomposition spectrum of NG correspond to nitric oxide, carbon monoxide, and formaldehyde (Figure 4). In contrast, the EGDN VUV spectrum is dominated by formaldehyde with minimal contribution from nitric oxide and carbon monoxide (data not shown). In general, differences in the VUV spectra of the nitrate esters are observed in the differing contribution of nitric oxide (142 -149 nm) and carbon monoxide (179-228 nm). In all cases, removal of the spectral contributions of these compounds from the nitrate ester VUV spectra resulted in broad featureless spectra consistent with the VUV spectra of water and oxygen (data not shown).

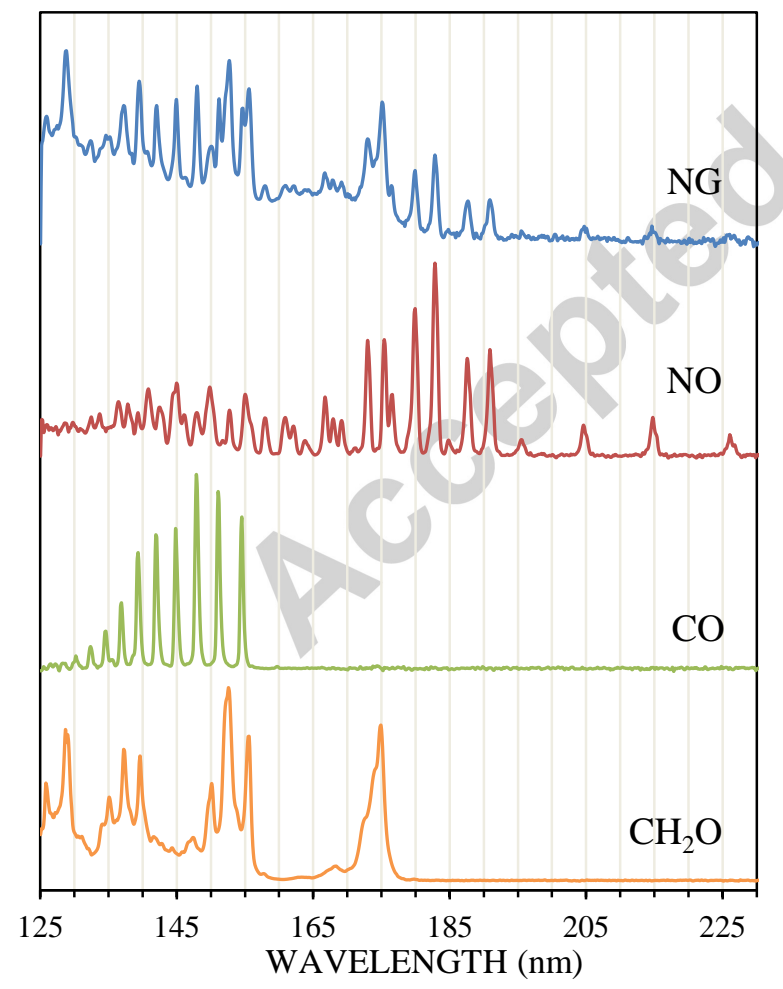

Fig. 4. VUV spectra of $\mathrm{NG}$ and three of its thermal decomposition products: $\mathrm{NO}, \mathrm{CO}$, and $\mathrm{CH}_{2} \mathrm{O}^{26}$.

As the VUV spectrophotometer follows the Beer-Lambert Law ${ }^{1,3,27}$, the absorptions of the decomposition products are additive to create the VUV spectra for each nitrate ester explosive. Therefore, the differentiation in the VUV spectra of EGDN, ETN, NG, and PETN at $280{ }^{\circ} \mathrm{C}$ could be attributed to the different stoichiometric ratios of the decomposition products. Spectral subtraction of 
nitric oxide, formaldehyde, carbon monoxide, water, and oxygen resulted in spectral multiplication factors that account for the differing contributions of each decomposition products.

As a check, the spectra of the decomposition products of NG were summed to attempt to recreate the NG spectra at $280{ }^{\circ} \mathrm{C}$ (Figure 5). This was accomplished by multiplying the absorbance values of each decomposition product by the factor determined by the spectral subtraction. This was repeated for all explosives, where the absorbance values for the decomposition products were summed and the squared correlation coefficient $\left(\mathrm{r}^{2}\right)$ and the sum of squares residual (SSR) ${ }^{3-5,11,28}$ were calculated between each summed spectrum and experimental spectrum to quantify the spectral similarities (Table 3 ). SSR is related to the $r^{2}$ through the following equation. ${ }^{29}$

$$
r^{2}=1-\frac{\text { sum of squares residual }}{\text { total sum of squares }}
$$

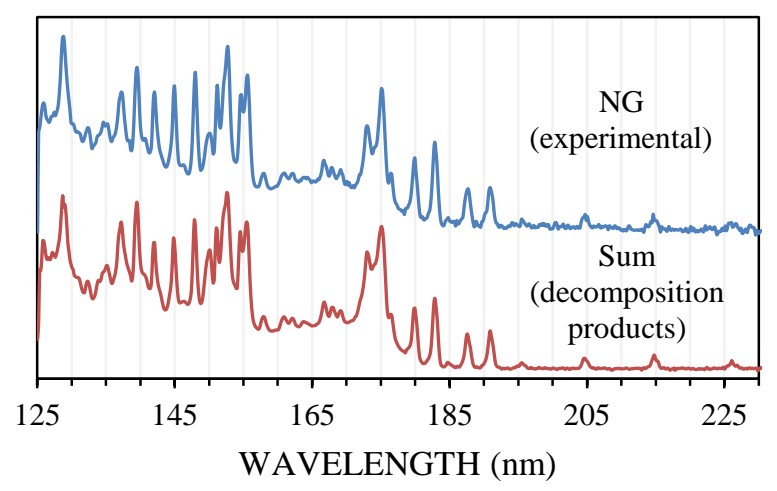

Fig. 5. Experimental VUV spectra of NG (top) and the calculated sum of NG thermal decomposition products (bottom) per Table 3.

Table 3. Relative percent composition of each decomposition product for EGDN, ETN, NG, and PETN at $280{ }^{\circ} \mathrm{C}$ and the squared correlation coefficients $\left(\mathrm{r}^{2}\right)$ and the sum of squares residual (SSR) between the summed components and the experimental spectra.

\begin{tabular}{cccccccc}
\hline & NO & $\mathbf{C O}$ & $\mathbf{C H}_{\mathbf{2}} \mathbf{O}$ & $\mathbf{H}_{\mathbf{2}} \mathbf{O}$ & $\mathbf{O}_{\mathbf{2}}$ & $\mathbf{r}^{\mathbf{2}}$ & SSR \\
\hline EGDN & $5 \%$ & $0 \%$ & $65 \%$ & $23 \%$ & $10 \%$ & 0.955 & 3.99 \\
ETN & $28 \%$ & $24 \%$ & $67 \%$ & $22 \%$ & $7 \%$ & 0.980 & 2.10 \\
NG & $35 \%$ & $40 \%$ & $66 \%$ & $30 \%$ & $15 \%$ & 0.978 & 3.44 \\
PETN & $14 \%$ & $17 \%$ & $56 \%$ & $26 \%$ & $13 \%$ & 0.955 & 4.52 \\
\hline
\end{tabular}

\subsection{Effect of Thermal Degradation on Sensitivity}

Comparison of peak area over the range of VUV flow cell temperatures reveal a greater sensitivity at lower temperatures for ETN and NG with greater peak area at lower temperatures (Figure 6). Indicating that pure ETN has a higher molar absorptivity than the sum of the decomposition products, and thus, resulting in a higher absorption and a greater sensitivity. PETN has variable responses to the changes in flow cell temperatures, while EGDN does not have significant changes in peak area with changing temperatures.

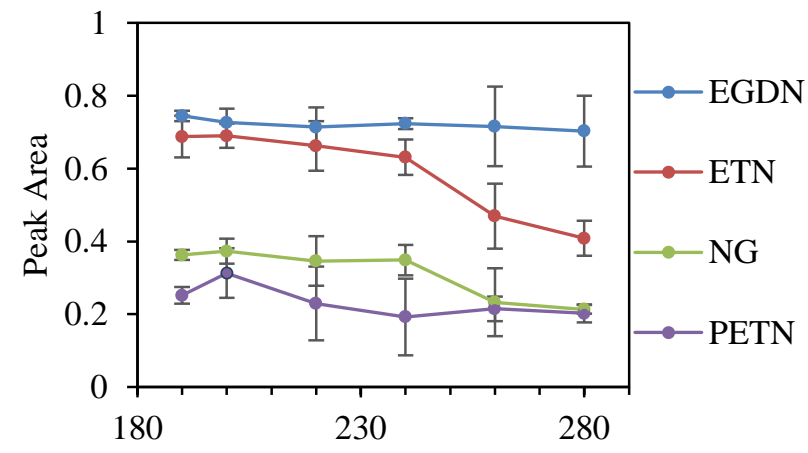

Flow Cell Temperature $\left({ }^{\circ} \mathrm{C}\right)$ 
Fig. 6. Effect of flow cell temperature on the peak area for nitrate ester explosives using a spectral filter from $128 \mathrm{~nm}-129 \mathrm{~nm}$.

\subsection{Analysis of Intact and Burned Double-Base Smokeless Powders}

A low split ratio of 5:1 provided the best response of all analytes with a total flow (split vent flow and column flow) of 10.8 $\mathrm{mL} / \mathrm{min}$. Note that a minimum total flow of $10 \mathrm{~mL} / \mathrm{min}$ is recommended for good chromatographic peak shape at low split ratios. ${ }^{22}$ Spectral filters were created using the VUVision software to enhance the chromatographic signal by averaging the absorption in specified wavelength ranges; much in the same way as with extracted ion chromatograms in mass spectrometry. ${ }^{9,12}$

All four of the nitrate ester decomposition VUV spectra absorbed light in the wavelength ranges 128 -129 nm; therefore, a spectral filter was created that averages the absorbances in this wavelength range to improve the detection limits of nitroglycerine. A spectral filter from 175-205 $\mathrm{nm}$ improved the detection of aromatic double base-smokeless powder components such as diphenylamine, ethyl centralite, and di-n-butyl phthalate (Figure 7).
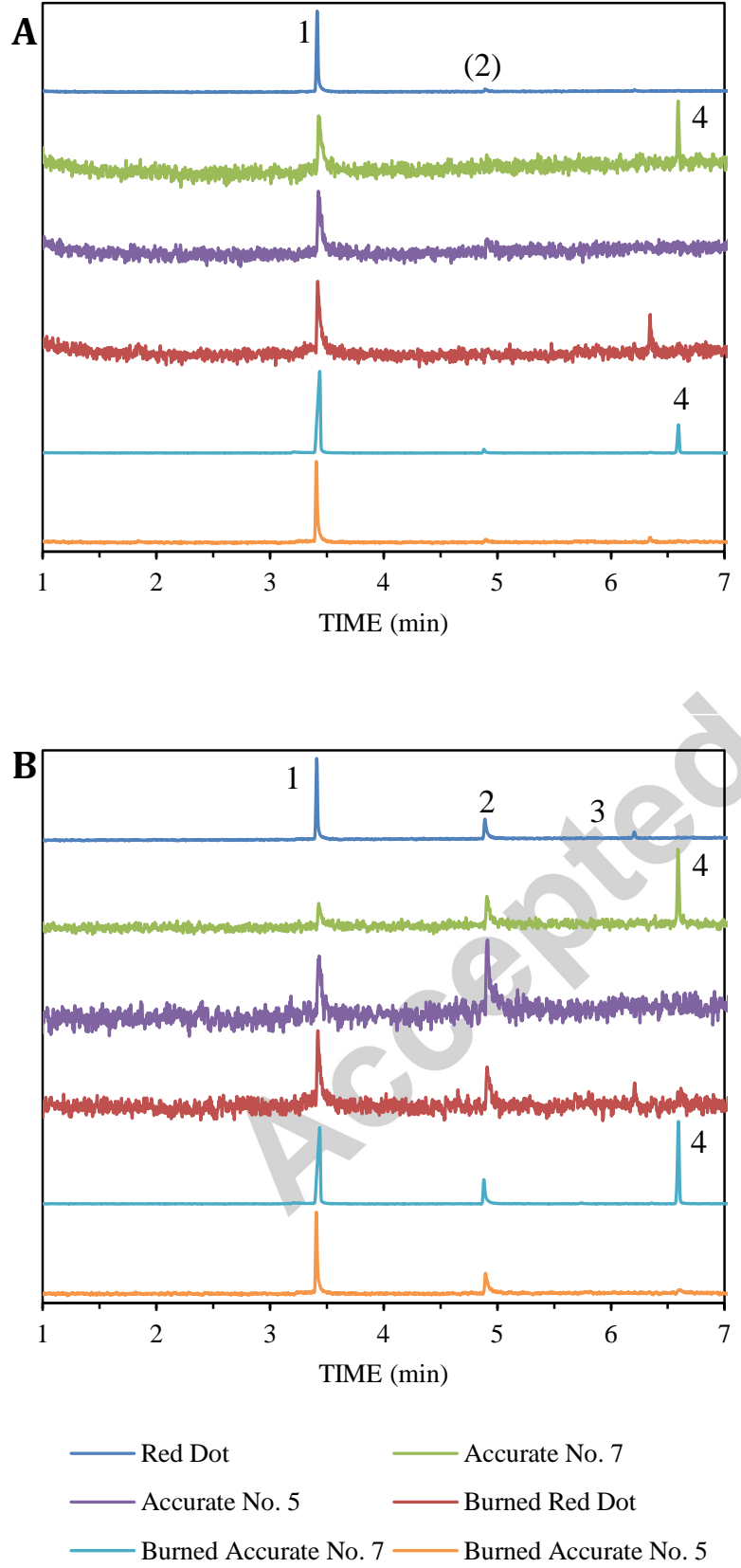

Fig. $7.5 \mathrm{mg}$ of intact and $50 \mathrm{mg}$ of burned Red Dot, Accurate No. 7 and Accurate No. 5 Double-Base Smokeless Powder with GC/VUV spectral filters (A) 175-205 nm, (B) 128-129 nm. (1) Nitroglycerine, (2) diphenylamine, (3) ethyl centralite, and (4) di-nbutyl phthalate. Each chromatogram normalized to unit absorbance. VUV spectra of smokeless powder components SI 4. 


\section{Conclusion}

GC/VUV has been used to investigate the thermal decomposition of nitrate ester explosives. In this work, increasing the transfer line and flow cell from $190^{\circ} \mathrm{C}$ to $280^{\circ} \mathrm{C}$ led to the decomposition of EGDN, ETN, NG, and PETN into nitric oxide, carbon monoxide, formaldehyde, water, and oxygen. It was determined that differing stoichiometric ratios of the decomposition products contribute to the variation in each nitrate ester explosive VUV spectrum. Additionally, GC/VUV was utilized to analyze realistic samples: double-base smokeless powders intact and burned (Red Dot, Accurate No. 5, and Accurate No. 7). Nitroglycerine, diphenylamine, ethyl centralite, and di-n-butyl phthalate were identified in the chromatograms of the realistic samples; thus establishing the potential of GC/VUV to analyse post-blast debris for double-base smokeless powders. However, further method optimization is necessary to improve the LODs of these nitrate ester explosive compounds for application to post-blast analysis.

\section{Acknowledgment}

CAC acknowledges a University Fellowship from IUPUI. This work was supported via a National Institute of Justice Award 2017-R2-CX0018 and 2018-R2-CX-0015. Opinions or points of view expressed here represent a consensus of the authors and do not necessarily represent the official position or policies of the U.S. Department of Justice.

\section{References}

1. Schug, K. A.; Sawicki, I.; Carlton, D. D.; Fan, H.; McNair, H. M.; Nimmo, J. P.; Kroll, P.; Smuts, J.; Walsh, P.; Harrison, D., Vacuum Ultraviolet Detector for Gas Chromatography. Analytical Chemistry 2014, 86 (16), 8329-8335.

2. Allegra, L.; Jonathan, S.; Changling, Q.; L., H. Z.; A., S. K., Detection of cannabinoids and cannabinoid metabolites using gas chromatography with vacuum ultraviolet spectroscopy. SEPARATION SCIENCE PLUS 2018, 1 (1), 37-42.

3. Schenk, J.; Mao, J. X.; Smuts, J.; Walsh, P.; Kroll, P.; Schug, K. A., Analysis and deconvolution of dimethylnaphthalene isomers using gas chromatography vacuum ultraviolet spectroscopy and theoretical computations. Analytica Chimica Acta 2016, 945, 1-8.

4. Changling, Q.; Jonathan, S.; A., S. K., Analysis of terpenes and turpentines using gas chromatography with vacuum ultraviolet detection. Journal of Separation Science 2017, 40 (4), 869-877.

5. Weston, C.; Smuts, J.; Mao, J. X.; Schug, K. A., Investigation of gas phase absorption spectral similarity for stable-isotopically labeled compounds in the 125-240nm wavelength range. Talanta 2018, 177, 41-46.

6. Gröger, T.; Gruber, B.; Harrison, D.; Saraji-Bozorgzad, M.; Mthembu, M.; Sutherland, A.; Zimmermann, R., A Vacuum Ultraviolet Absorption Array Spectrometer as a Selective Detector for Comprehensive Two-Dimensional Gas Chromatography: Concept and First Results. Analytical Chemistry 2016, 88 (6), 3031-3039.

7. Bai, L.; Smuts, J.; Schenk, J.; Cochran, J.; Schug, K. A., Comparison of GC-VUV, GC-FID, and comprehensive two-dimensional GC-MS for the characterization of weathered and unweathered diesel fuels. Fuel 2018, 214, 521-527.

8. Bai, L.; Smuts, J.; Walsh, P.; Qiu, C.; McNair, H. M.; Schug, K. A., Pseudo-absolute quantitative analysis using gas chromatography Vacuum ultraviolet spectroscopy - A tutorial. Analytica Chimica Acta 2017, 953, 10-22.

9. Santos, I. C.; Smuts, J.; Choi, W.-S.; Kim, Y.; Kim, S. B.; Schug, K. A., Analysis of bacterial FAMEs using gas chromatography - vacuum ultraviolet spectroscopy for the identification and discrimination of bacteria. Talanta 2018, 182, 536-543.

10. Walsh, P.; Garbalena, M.; Schug, K. A., Rapid Analysis and Time Interval Deconvolution for Comprehensive Fuel Compound Group Classification and Speciation Using Gas Chromatography-Vacuum Ultraviolet Spectroscopy. Analytical Chemistry 2016, 88 (22), 11130-11138.

11. Skultety, L.; Frycak, P.; Qiu, C.; Smuts, J.; Shear-Laude, L.; Lemr, K.; Mao, J. X.; Kroll, P.; Schug, K. A.; Szewczak, A.; Vaught, C.; Lurie, I.; Havlicek, V., Resolution of isomeric new designer stimulants using gas chromatography - Vacuum ultraviolet spectroscopy and theoretical computations. Analytica Chimica Acta 2017, 971, 55-67.

12. Weber, B. M.; Walsh, P.; Harynuk, J. J., Determination of Hydrocarbon Group-Type of Diesel Fuels by Gas Chromatography with Vacuum Ultraviolet Detection. Analytical Chemistry 2016, 88 (11), 5809-5817.

13. Anthony, I. G. M.; Brantley, M. R.; Gaw, C. A.; Floyd, A. R.; Solouki, T., Vacuum Ultraviolet Spectroscopy and Mass Spectrometry: A Tandem Detection Approach for Improved Identification of Gas Chromatography-Eluting Compounds. Analytical Chemistry 2018, 90 (7), 4878-4885.

14. Beveridge, A., Forensic Investigation of Explosions. 2 ed.; Taylor \& Francis: 2011; p 696.

15. Zhao, X.; Yinon, J., Identification of nitrate ester explosives by liquid chromatography-electrospray ionization and atmospheric pressure chemical ionization mass spectrometry. Journal of Chromatography A 2002, 977 (1), 59-68.

16. Beveridge, A., Forensic Investigation of Explosions. 2 ed.; Taylor \& Francis: 2011; p 636, 696.

17. Committee, T. L. E. G. S. P. Recommended Guidelines for Forensic Identification of Post-Blast Explosive Residues; 2007.

18. Takáts, Z.; Wiseman, J. M.; Cooks, R. G., Ambient mass spectrometry using desorption electrospray ionization (DESI): instrumentation, mechanisms and applications in forensics, chemistry, and biology. Journal of Mass Spectrometry 2005, 40 (10), 1261-1275.

19. Garcia-Reyes, J. F.; Harper, J. D.; Salazar, G. A.; Charipar, N. A.; Ouyang, Z.; Cooks, R. G., Detection of Explosives and Related Compounds by Low-Temperature Plasma Ambient lonization Mass Spectrometry. Analytical Chemistry 2011, 83 (3), $1084-1092$.

20. Rowell, F.; Seviour, J.; Lim, A. Y.; Elumbaring-Salazar, C. G.; Loke, J.; Ma, J., Detection of nitro-organic and peroxide explosives in latent fingermarks by DART- and SALDI-TOF-mass spectrometry. Forensic Science International 2012, 221 (1), 84-91.

21. Jan, A.; Ludmila, L. A.; Johan, D.; Bengt-Harald, J., Analysis of Explosives by GC-UV. Journal of Forensic Sciences 2017, 62 (4), 10221027.

22. Rood, D., Gas Chromatography Problem Solving and Troubleshooting. Journal of Chromatographic Science 1998, 36 (9), $476-477$.

23. ThermoFisherScientific, OMNIC Picta User Guide. 2009. 
24. Lide, D. R., CRC Handbook of Chemistry and Physics. CRC Press, Taylor \& Francis: Boca Raton, FL, 2007; p 3-232.

25. Leppert, J.; Härtel, M. A. C.; Klapoetke, T. M.; Boeker, P., Hyper-fast Flow-Field Thermal Gradient GC/MS of Explosives with reduced elution temperatures. Analytical Chemistry 2018.

26. VUVAnalytics, VUV Spectral Database. Austin, TX, 2018.

27. Fan, H.; Smuts, J.; Walsh, P.; Harrison, D.; Schug, K. A., Gas chromatography-vacuum ultraviolet spectroscopy for multiclass pesticide identification. Journal of Chromatography A 2015, 1389, 120-127.

28. Schenk, J.; Nagy, G.; Pohl, N. L. B.; Leghissa, A.; Smuts, J.; Schug, K. A., Identification and deconvolution of carbohydrates with gas chromatography-vacuum ultraviolet spectroscopy. Journal of Chromatography A 2017, 1513, 210-221.

29. Draper, N. R., Applied regression analysis. 3rd ed. ed.; Smith, H., Ed. Wiley: New York :, 1998; pp 15 - 45.

\section{Highlights:}

- Coupling gas chromatography to vacuum UV spectroscopy can identify explosives at part-permillion levels.

- Increased flow cell temperatures resulted in thermal degradation of the explosives into reproducible and complex mixtures of gaseous products such as nitric oxide, carbon monoxide and formaldehyde 
Corrigendum to "Generating highly specific spectra and identifying thermal decomposition products via Gas Chromatography / Vacuum Ultraviolet Spectroscopy (GC/VUV): Application to nitrate ester explosives" [Talanta 195 (2019) 580-586]

The authors regret that the labels for NG and ETN were reversed in Figs. 1-5, and in Table 3.

The authors would like to apologise for any inconvenience caused.

Table 3. Relative percent composition of each decomposition product for EGDN, ETN, NG, and PETN at $280^{\circ} \mathrm{C}$ and the squared correlation coefficients $\left(r^{2}\right)$ and the sum of squares residual (SSR) between the summed components and the experimental spectra.

\begin{tabular}{|c|c|c|c|c|c|c|c|}
\hline & NO & $\mathrm{CO}$ & $\mathrm{CH}_{2} \mathrm{O}$ & $\mathrm{H}_{2} \mathrm{O}$ & $\mathrm{O}_{2}$ & $\mathrm{r}^{2}$ & SSR \\
\hline EGDN & $5 \%$ & $0 \%$ & $65 \%$ & $23 \%$ & $10 \%$ & 0.955 & 3.99 \\
\hline NG & $28 \%$ & $24 \%$ & $67 \%$ & $22 \%$ & $7 \%$ & 0.980 & 2.10 \\
\hline ETN & $35 \%$ & $40 \%$ & $66 \%$ & $30 \%$ & $15 \%$ & 0.978 & 3.44 \\
\hline PETN & $14 \%$ & $17 \%$ & $56 \%$ & $26 \%$ & $13 \%$ & 0.955 & 4.52 \\
\hline
\end{tabular}

